\title{
PERTEMUAN KYAI PENOPPO1 DAN SOSRO KOESOEMO I2: Studi Tentang Gerakan Sosial di Afdeeling Berbek 1832 M
}

\author{
Depy Tri Budi Siswanto \\ Program Studi Pendidikan Sejarah, Fakultas Keguruan dan IImu Pendidikan, Universitas \\ Nusantara PGRI Kediri, Kota Kediri \\ depysiswanto@gmail.com \\ Latif Kusairi \\ Peneliti PUSDEHAM Surabaya; Alumnus Pascasarjana IImu Sejarah UGM \\ latif_ks@yahoo.co.id
}

\begin{abstract}
Abstrak
Gerakan sosial lahir akibat terjadinya tindakan represif pemegang suzereinitas kepada rakyat. Regulasi yang mengikat rakyat khususnya dibidang sosial dan ekonomi membuat masyarakat terintegrasi untuk melakukan perlawanan. Hal ini merupakan bagian dari pertentangan kelas untuk mendapatkan keadilan. Afdeeling Berbek yang secara de jure merupakan daerah kekuasaan kolonial ini, sempat mendapat badai karena gerakan sosial tersebut. Kyai Penoppo merupakan tokoh yang secara historis dihormati sebagai pemuka agama dan pemimpin dalam perlawanan tindakan subversif kolonial di Afdeeling Berbek. Perlawanan ini terjadi ketika suzereinitas Afdeeling Berbek dipegang oleh Sosro Koesoemo I (Kanjeng Jimat). Kebijakan yang dikeluarkan Sosro Koesoemo I tentu keseluruhannya di pengaruhi oleh kebijakan pusat yaitu Karesidentie Kediri ataupun langsung dari Batavia. Pengaruh Kiai Penoppo di Nganjuk hingga saat ini masih kental terasa, sama halnya dengan Sosro Koesoemo I (Kanjeng Jimat). Tinjauan historis ini mencoba menjelaskan hubungan eksistensi dua tokoh besar tersebut kaitannya dalam gerakan sosial.
\end{abstract}

Kata Kunci : Afdeeling Berbek, eksistensi, Regulasi

\footnotetext{
1 Lebih dikenal sebagai Kyai Ngaliman Guru Ageng.

2 Lebih dikenal sebagai Kanjeng Jimat.
} 


\section{A. PENDAHULUAN}

Rakyat merupakan unsur terpenting dalam pemerintahan. Menjadi pola umum ketika rakyat tertindas oleh kebijakan stick holder, maka akan lahir perlawanan dalam bentuk pemikiran hingga fisik. Perlawanan pemikiran tertuang dalam tulisan-tulisan yang nantinya malah mengobarkan semangat juang dari kaum tertindas untuk mengakhiri tindakan represif tersebut. Semen-tara itu, perlawanan fisik merupakan wujud klimaksnya penindasan tersebut

Dalam perjalanan panjang sejarah, tindakan ofensif wong cilik terhadap kepemimpinan yang subversif selalu memiliki pemimpin yang hebat. Pemimpin ini memiliki kelebihan dari pada yang lain, atau terkadang sang pemimpin adalah tokoh yang paling dilukai/ dirugikan oleh kebijakan penguasa daerah tersebut.

Pemikiran dari seorang pemimpin perlawanan atau pergerakan dipengaruhi oleh lingkungannya, pendidikannya, ataupun agama ${ }^{3}$ (nya).

3 Agama juga merupakan point dalam diskusi jurnal ini. Bagaimana agama sebagai landasan dasar timbulnya gerakan sosial. Mengenai agama, menurut Allan Manzies, dunia belum menemukan sepenuhnya, namun masih dalam proses mencari tahu, apa itu agama. Agama adalah
Opsi yang terakhir menjadi pola umum dalam pergerakan dalam arus sejarah Indonesia. Tentu yang dimaksud peneliti adalah agama Islam.

Islam berarti penyerahan dan Muslim berarti orang yang menyerahkan dirinya kepada satu-satunya Tuhan. ${ }^{4}$ Para muslim memiliki keyakinan yang kuat tentang melawan suatu peninda-san ataupun melawan suatu penjajahan. Hal ini disebut oleh mereka sebagai berjihad. Aktifitas perlawanan yang mengorbankan jiwa dan raga namun memiliki imbalan yang sesuai.

Perlawanan semacam ini sangat populer ketika masa kolonialisme dan imperialisme Belanda di Indonesia. Pergerakan ini muncul di Sumatera, Kalimantan, Sulawesi dan mungkin yang paling kuat terjadi di Jawa. Agaknya perlawanan Diponegoro ${ }^{5}$ menjadi

penyembahan kepada kekuatan yang lebih tinggi. Max Muller menjelaskan bahwa agama adalah kemampuan atau disposisi mental yang tidak bergantung pada, bahkan, meskipun ada, perasaan dan penalaran, memungkinkan manusia untuk memahami Yang Tak Terbatas dengan nama yang berbedabeda dan dalam berbagai penyamaran. Lihat Allan Manzies, History of Religion: Sejarah Kepercayaan dan Agama-agama Besar Dunia, (Yogyakarta: Indoliterasi, 2015), hlm. $7-9$

${ }^{4}$ Ibid., hlm. 240-241.

5 Oleh Willem van Hogendorp Dipnonegoro disebut sebagai penggerak perang besar ini: A special characteristic 
semacam cambuk untuk melawan kolonial di Jawa.

Suatu wilayah di Jawa yang dikuasai kolonial juga pernah mengalami kegoncangan ini. Karisidenan Kediri merupakan bagian dari kekuasaan Kolonial dalam perjanjian lama antara hegemoni lokal (Kasunanan dan Kasultanan) dengan Kolonial. ${ }^{6}$ Wilayah dari Karisiden Kediri lumayan luas dan

about Diponegoro in the view of the Javanese, who are always extremely exalted and distants in their dealings between superiors and inferiors, is that he consorts as easily with the common man as with the great ones (and) because of this has made himself much loved everywhere. Lihat Peter Caray, Pangeran Diponegoro (1785-1855): A Leader Made not Born, hlm. 1. Peter Carey dalam Seminar Nasional Dies Natalis ke-54 Universitas Diponegoro: Menggali Perjuangan Pahlawan Diponegoro Untuk Penyusunan Materi Pendidikan Karakter Bangsa di Hotel Horison Semarang, 8 Oktober 2011.

${ }_{6}$ Perjanjian Giyanti merupakan awal dari semua ini. Dalam Perjanjian Giyanti disepakati akan dilaksanakannya Pilihan Nagari (Pembagian wilayah tanah Jawa menjadi dua bagian, yakni Kasunanan Surakarta dan Kasultanan Yograkarta). Dalam pembagian tersebut maka terjadi pula pembagian yang melibatkan wilayah kediri dan Nganjuk. Sebut saja wilayah Kediri dan Pace (Nganjuk) dikuasai Pakubuono, Kertosono dikuasai Mangkubumi. Hal ini bertahan beberapa dekade dan kemudian politik devide et empera Belanda semakin memecah belah hegemoni Jawa. Lihat Sri Wintala Achmad, Babad Giyanti, Pilihan Nagari dan Perjanjian Salatiga, (Yogyakarta: Araska, 2016), hlm.182-183. Perjanjian lain yang berhubungan dengan perpecahan ini adalah Perjanjian Salatiga dan Perjanjian Sepreh. merupakan bagian dari karisidenan besar di bawah kolonial.

Daerah-daerah bagian yang dikuasai Karisidentie Kediri pada dekade 1830 M, dapat dilihat dalam ANRI. Besluit, Semarang, 31 Agustus $1830 \mathrm{~L}^{\mathrm{a}}$. No. 1., bahwa konverensi anara Komisaris-komisaris dan Gubernur Jenderal menyatakan dalam poin ke-3 yaitu,

Bahwa Residensi Keidri akan terdiri dari Kabupaten-kabupaten (Afdeeling): Kedi-rie, Kertosono, Ngandjook, Brebek, Ngrowo, dan Kalang-bret dan selanjutnya dari Distrikdistrik: Blitar, Treng-galek, Kam-pak, dan semua lain-nya lebih ke Timur sam-pai dengan batas-batas dari Malang; batasbatas dari kab-upaten-kabupaten dan distrik-distrik juga akan diatur kemudian. ${ }^{7}$

Pemerontakan dalam wilayah Karisidenan Kediri ini terjadi di Afdeeling Berbek daerah yang berada di sebelah utara dari Kediri. Dalam sumber yang didapat peneliti yaitu ANRI. Encyclopaedie van Nederlanche Indie 1919 menjelaskan bahwa, Afdeeling Berbek merupakan daerah dari Karesiden Kediri yang memiliki luas 1103 $\mathrm{km}^{2}$, dan memiliki 5 distrik dengan nama

7 ANRI. Besluit, Semarang, 31 Agustus 1830 La. №. 1. 
Ngandjoek, Berbek, Lengkong, dan Waroedjajeng. ${ }^{8}$

Afdeeling yang baru berdiri sekitar tahun $1830^{9}$ ini dipimpin oleh Sosro Koesoemo I. Setidaknya tahun pemerintahanya ini masih menuai kebingungan sejarawan lokal dalam menentu-kannya. Hal ini terkorelasikan dengan candrasang-kala yang berada di Masjid Yoni Al-Mubarok Berbek.

Dimungkinkan bahwa pemberontakan ini terjadi pada masa Sosro Koesoemo I. Pemberontakan tokoh yang paling terkenal dinganjuk ini terjadi pada tahun 1832 M. Hal ini dibuktikan dengan beberapa arsip dan laporan politik pada tahun-tahun sekitar $1832 \mathrm{M}$.

Aktor intelektual dari pemberontakan ini adalah seorang Kyai, yang dikeal dengan nama Kyai Ngliman Guru Ageng atau boleh peneliti sebut dengan nama yang kurang populer, yaitu Kyai Pennopo ${ }^{10}$. Dapat dipastikan kedua

8 ANRI. Encyclopaedie van Nederlanche Indie. 1919. Martinus Nijhof: s' Grevenhage.

${ }^{9}$ Setidaknya setelah Berbek disebut sebagai Afdeeling.

10 Alasan peneliti menggunakan nama (Kyai) Penoppo adalah karena, ada tendensi nama ini sengaja dilupakan ataupun dihilangkan dengan alasan tertentu oleh sebagian kalangan. Hingga penulisan ini selesai, peneliti masih mencari alasan, mengapa tendensi tersebut terjadi. Alasan nama ini dimiliki oleh orang yang sama, dan orang tersebut adalah nyata. Mengingat banyak sekali folklor yang tenang ketokohan Kyai Penoppo tersebut.

Perlawanan yang dilaku-kan oleh Penoppo adalah terkait pajak. Beban pajak yang harus ditangung masyarakat Ngliman dirasa tidak sesuai dengan faktor historis kewilayahan tersebut yang pernah mendapatkan Sima Swatantra. Perlawanan ini sangat berunsur agama karena penokohan Pennopo yang merupakan seorang ulama.

Selama proses pemberon-takan ini berlangsung, Penoppo juga melakukan konsolidasi dengan orangorang berpengaruh, atau orang yang pernah berpengaruh. Perjalannan ofensif-nya ini dapat dibilang sangat bernyali. Beberapa catatan kolonial mengungkapnya, bahwa Penoppo pernah mendatangi beberapa tokoh penting seperti Kepala Residensi Kediri, assisten Ngawi dan lain sebagainya.

Tulisan ini mencoba untuk menakar perlawanan yang dilakukan

lain yang digunakan peneliti adalah karena menurut hemat peneliti nama dari tokoh besar ini adalah Penoppo, sedangkan disebut (Kyai) Ngliman karena dikenalnya atau poros perjuangan tokoh ini berada di Ngliman dan dimungkinkan penguburannya juga disini. Untuk itulah Kyai Penoppo juga disebut dengan Kyai Ngliman. 
Pennopo terhadap kuasa kolonial. Khususnya persentuhan dua popularitas besar dan berpengaruh hingga saat ini yaitu Penoopo dengan Sosro Koesoemo I. Tidak ketinggalan, bagaimana dimensi agama dapat sangat berpengaruh dalam perlawanan ini.

\section{B. METODE PENELITIAN}

Sebenarnya metode penelitian kualitatif jenis studi kasus sangat relevan dengan penulisan ini, namun kajian peneliti ini akan lebih condong menggunakan sumber-sumber historis. Pegkajian ini memandang pula perlawanan gerakan sosial dalam konteks historis. Untuk itu metode penelitian sejarah (historis) merupakan alat yang paling tepat.

Penelitian Historis terdiri dari empat sintak penelitian, yaitu heuristik, kritik, interpretasi dan historiografi. Pengumpulan sum-ber (heuristik) yang dilakukan peneliti, menghasilkan temuantemuan sum-ber primer (Revolutie, 21 Pebruari 1832., No. 29., ANRI. Besluit, Semarang, 31 Agustus 1830 La. No. 1., dan lain-lain) dan sumber-sumber sekunder yang tersaji dalam daftar pustaka. Sumber-sumber ini sudah mengalami proses kritik (kritik sumber: Intern/ekstern). Adapun interpretasi (penafsiran, penghubungan fakta) sangat lekat denga historiografi (penulisan sejarah) yang langsung tersaji dalam hasil dan pembahasan.

\section{HASIL DAN PEMBAHASAN}

\section{Dimensi Agama dalam Gerakan}

\section{Sosial Kyai Penoppo}

Perlawanan yang dilakukan oleh Penoppo bukan perlawanan individu. la dapat memobilisasi masyarakat lokal untuk melakukan perlawanan. Untuk itu perlawanan ini merupakan bentuk gerakan sosial.

Menurut Giddens, gerakan sosial merupakan sebuah gerakan yang dilakukan secara bersama-sama demi mencapai tujuan yang sama-sama diinginkan oleh kelompok atau dengan kata lain gerakan sosial adalah tindakan kolektif untuk mencapai keinginan yang menjadi cita-cita bersama. ${ }^{11}$ Sementara itu, Tarrow menempatkan gerakan sosial sebagai politik perlawanan yang terjadi ketika rakyat biasa yang bergabung dengan para kelompok masyarakat yang lebih berpengaruh menggalang kekuatan

${ }^{11}$ Muhammad Lauhil Mahfud, "Gerakan Sosial Pembangunan dan Pelestarian Lingkungan di Jalur Pendakian Gunung Penanggungan Desa Tamiajeng, Kecamatan Trawas, Kabupaten Mojokerto", (Surabaya: Universitas Islam Negeri Sunan Ampel), hlm. 32. 
untuk melawan para elit, pemegang otoritas, dan pihak-pihak lawan lainnya. ${ }^{12}$

Tidak dapat dipungkiri bahwa perlawanan yang dilakukan Kyai Penoppo merupakan gerakan sosial yang sangat masiv. Selain aspek jihad Islam yang dimasukan dalam perlawanan Kyai Penoppo. Superioritas seorang Kyai Penoppo juga sangat menentukan perlawanan ini. Kyai Penoppo merupakan seorang ulama yang membela masayarakat Ngliman karena beban pajak dan kerja wajib yang sangat berat. Motif lain yang diinginkan Penoppo lebih bersifat kepentingan pribadi. Pasca bombardir pasukan Sosro Koeseomo I terhadap Penoppo, Landrad Kediri melakukan pendekatan dengan Penoppo, dan Penoppo dalam perdamaian ini menginginkan (mengusulkan) agar makam nenek moyangnya, semua garis keturunan Sultan Giri di Daerah Gersik dan masjid diperlakukan secara pantas, namun ditoak. $^{13}$ Hal ini menunjukan bahwa Penoppo sebagai ulama sangat berpengaruh dalam perlawanan di Afdeeling Berbek tersebut.

Ulama merupakan posisi yang sangat dimuliakan. Tidak hanya karena

\footnotetext{
12 Ibid..

${ }^{13}$ ANRI, Resolusi 21 Pebruari 1832,
} No. 29., Proses Verbal 24 Januari 1832. kealiman, tapi juga disebabkan oleh kharisma mereka. Sehingga sosok Kiyai memberikan pengaruh yang cukup besar terhadap struktur sosial dan begitu bagi kehidupan sosial. Pada akhirnya, pengaruh kiyai tersebut membentuk spektrum Islam tradisional-sebuah Islam yang sangat berbeda adanya dengan Islam modern sebagai yang dipahami oleh teknokrat muslim. Islam yang tidak hanya sebatas ritual semata, tapi Islam sebagai sebuah spirit yang mewarnai seluruh aspek hidup santri dan umat. ${ }^{14}$

Maka apa yang dilakukan ulama akan diikuti para umatnya. Begitupula untuk berjihad. Islam mengajarkan agar melawan dan berusaha untuk bebas dari penjajahan dan penindasan. Begitupula dengan keadaan di Afdeeling Berbek pada waktu itu, dimana sistem kerja wajib dan pajak semakin berat, sementara kekuasaan kolonial semakin kuat. Hal ini sama halnya penabuhan genderang perang antara kaum tertindas dengan kolonial di Afdeeling Berbek. Kyai Penoppo sebagai ulama yang tentu tidak menerima penindasan tersebut

14 Dinul Husnan dan Hhd. Sholihin, "Ulama, Islam, dan Gerakan Sosial-Politik: Reposisi Ulama dalam Gerakan Sosio-Politik di Islam di Indonesia", J Kajian Keislaman dan Kemasyarakatan 2017, 2 (1): 1-25., hlm. 2-3. 
mencoba untuk melawan kolonial dengan segala kemampuan yang ada.

Peran elit agamawan dalam gerakan sosial sudah mendapat banyak perhatian dalam literatur ilmu politik. Politik perlawanan yang melibatkan pemuka agama, semacam kyai, ulama, pendeta dan sebagainya biasanya tampil dalam bentuk-bentuk masyarakat tradisional di mana agama memiliki peran penting di tengah masyarakat. Pemuka agama memiliki kedudukan yang sangat istimewa dalam masyarakat pedesaan. Mereka tidak mesti memiliki wewenang politik atau menduduki jabatan tertentu dalam struktur politik lokal. Namun kekuatan karisma yang dimiliki pemuka agama inilah yang kemudian memiliki arti penting bagi masyarakat di mana pemuka agama tersebut berdiam. ${ }^{15}$

\section{Mengenal Kyai Penoppo dan Sosro Koesomo I}

Ketika wisata spiritual di Nganjuk disebutkan, maka makam dari Kyai Penoppo (Mbah Ngliman) dan makam Sosro Koesoemo I (Kanjeng Jimat) yang akan dikenal. Dua tokoh besar yang

15 Ubaidillah, "Kyai Kampung dalam Mobilisasi Pelawanan Petani Pada Konflik Lahan di Urutsewu Kebumen", (Yogyakarta: Universitas Gajah Mada, 2014), hlm. 1. pernah memiliki supremasi agama dan politik di Nganjuk. Dimasa lampau mereka adalah dua kekuatan yang pernah berbenturan. Dimasa kini mereka masih memiliki pengaruh bagi masyarakat Nganjuk dan luar Nganjuk dalam hubungannya dengan agama dan tuhan.

Menarik jika membahas tulisan dari para sejarawan lokal Nganjuk mengenai pemberontakan Kyai Pennopo. Terdapat beberapa literasi yang diterbitkan maupun tidak, yang ditulis oleh perseorangan, kelompok, maupun lembaga pemerintah Kabupaten Nganjuk yang berbeda dalam menjelaskan siapa lawan dari Kyai Pennopo dan tahun perlawannaya.

Menurut Dinas Pariwisata dan Kebudayaan Daerah Kabupaten Nganjuk 2006, pemberontakan Kyai Pennopo terjadi pada masa pemerintahan Sosrokoesoemo II.16 Sementara itu, Menurut Damari, dkk., pemberontakan tersebut terjadi pada masa pemerintahan

16 Dinas Pariwisata dan Kebudayaan Daerah Kabupaten Nganjuk, Bunga Ramapi Sejarah dan Ceritera Lokal Kabupaten Nganjuk, (Nganjuk: Dinas Pariwisata dan Kebudayaan Kabupaten Nganjuk, 2006), hlm. 5. 
Sosrodirejo, bupati kedua Afdeeling

Berbek. ${ }^{17}$

Kontradiksi tersebut merupakan hasil dari interpretasi peneliti. Begitu pula dalam tulisan ini, penulis tendensius untuk menyatakan bahwa pemberontakan Kyai Penoppo terjadi pada masa Sosro Koesoemo I. Sudah jelas dalam ANRI, Resolusi 21 Pebruari 1832, No. 29.18, Proses Verbal 24 Januari 1832., bahwa, "Sosro Koesoemo sebagai bupati Berbek menghancurkan pertahanan Kyai Ngliman". ${ }^{19}$

17 Damari, Samsul Hadi, dan Aries Trio Efendy, Kabupaten Pace Dalam Lintas Sejarah, (Nganjuk: Kantor Perpustakaan dan Arsip Kabuapten Nganjuk, 2014), hlm. 32.

18 Dalam Resolutie, 21 Pebruari 1832, No. 29., didalamnya terdapat beberapa surat dari Pejabat Hindia beranama P. Merkus. Surat tersebut keseluruhan ditulis untuk Gubernur Jendral di Batavia. Sementara itu, ada beberapa surat terdiri dari proses verbal, yaitu percakapan yang ditulis antara $P$. Merkus dengan orang-orang yang bersangkutan dalam pemberontakan Kyai Ngliman. Suratsurat yang dimaksud peneliti terdiri dari: (1) Proses Verbal 24 Januari 1832, (2) Laporan Merkus tentang penagkapan Kyai Ngliman kepada Gubernur Jendral 28 Januari 1832, No. 40; (3) Keputusan Pemerintah dalam Revolusi 1 Pebruari 1832, No. 29; (4) Surat Merkus kepada Gubernur Jendral 4 Pebruari 1832, No. 48; (5) Surat Merkus kepada Gubernur Jendral 4 Pebruari 1832, No. 49; (6) Surat Merkus kepada Gubernur Jendral 4 Pebruari 1832, No. 51. Peneliti mendapatkan terjemahan-terjemahan dari surat-surat tersebut, dan jurnal ini sebagian besar disusun atas sumber-sumber tersebut.

${ }^{19}$ ANRI, Resolusi 21 Pebruari 1832, No. 29., Proses Verbal 24 Januari 1832. Dari
Kemudian, berdasarkan tahun pemerintahan dari Sosro Koeseomo I pada tahun (......-1832/35/38) ${ }^{20}$ maka jelas sekali Sosro Koesoemo yang disebut dalam catatan kolonial tersebut adalah Sosro Koesoemo I.

Aksentuasi Penoppo dan Sosro Koeseomo I dalam jurnal ini, menjadi kurang esensial tanpa menampilkan profil dari kedua tokoh besar tersebut. Boleh katakan penjabaran profil berikut setengah eksplisit, peneliti seolah masih meraba, karena memang data primer untuk kedua tokoh tersebut sulit didapatkan.

\section{a. Kyai Penoppo}

Kyai Ngaliman (Ngliman) atau

Kyai Penoppo adalah tokoh militan,

nama Raden Tumenggung Sosro Koesoemo yang disebut dalam catatan pemerintah kolonial tersebut, dapat dikonklusikan bahwa pemberontakan yang dilakukan Kyai Penoppo tidak dilakukan pada masa pemerintahan Sosrodirejo, bupati kedua Afdeeling Berbek. Begitupula, pemeberontakan ini tidak terjadi di masa pemerintahan Sosro Koesoemo II, karena tahun pemerintahanya pada tahun $1844 \mathrm{M}$ dan mangkatnya $1852 \mathrm{M}$. Lihat ANRI, No. 1240. Kediri, 28 Agustus 1852.

20 Tahun 1835 didapat dari konversi tahun $1251 \mathrm{H}$ menjadi Masehi. Sementara itu, tahun 1838 didapat dari konversi candrasangkala: Leno Saroso Pandito Iku (1760 S) menjadi Masehi. Tahun tersebut masih membingungkan, ketika penulisan jurnal ini selesai, peneliti masih menelaah berkali-kali tentang kapan sebenarnya Sosro Koesoemo I mulai memerintah, akhir pemerintahan, dan kematianya. 
pejuang rakyat era kolonial di Karesiden

Kediri. Lebih khusus lagi, daerah perlawananya dilakukan di Afdeeling Berbek, atau sekarang bisa disebut wilayah Kabupaten Nganjuk. Bukti fisik perjuanganya yang masih ada hingga sekarang adalah makam.

Makam Kyai Penoppo berada di Desa Ngliman, Kecamatan Sawahan, Kabuapten Nganjuk. Daerah tersebut berjarak sekitar $25 \mathrm{KM}$ dari pusat kota. ${ }^{21}$ Makam tersebut dikunjungi bahkan oleh orang-orang diluar Jawa Timur. Hal ini menunjukan bahwa pengaruh Ngaliman masih terasa sampai sekarang.

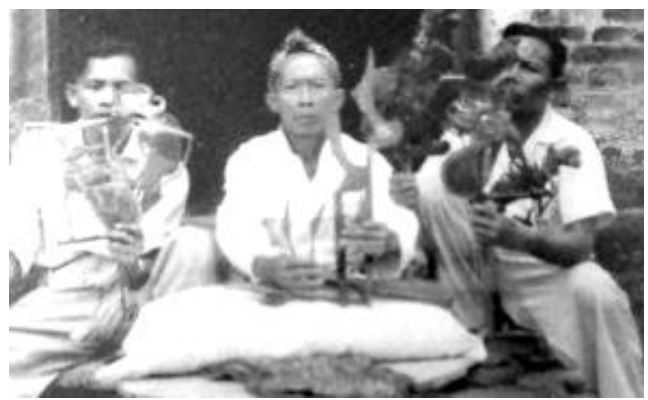

Gambar 1. Pusaka Kyai Ngliman22

Kyai Penoppo bukan orang Nganjuk asli. Mengenai keterlibatanya pada masalah pajak di Nganjuk, ada yang berpendapat Ngliman merupakan menantu Sunan Giri dan Penoppo merupakan keturunan Kyai Ngliman. Hak

${ }^{21}$ Badan Pusat Statistik Kabupaten Nganjuk, Kabupaten Nganjuk dalam Angka 2017, (Nganjuk: BPS Kabupaten Nganjuk, 2017), hlm. 10.

${ }^{22}$ Koleksi Arsip Foto Kabupaten Nganjuk. prerogratif nenek moyangnya diingkari oleh pemerintahan kolonial di Afdeeling Berbek, untuk itu ia melakukan perlawanan. Sumber ini secara implisit menyatakan perbedaan tokoh Kyai Penoppo dan Ngliman. ${ }^{23}$ Padahal dalam Laporan Politik Tahun 1837 jelas menyebutkan bahwa "Kyai Penoppo atau terkenal dengan sebutan Kyai Ngliman Guru Ageng". 24

Dalam sumber pertama diatas, berarti ada tendensi untuk menyatakan adanya hubungan Sunan Giri dengan daratan Nganjuk khususnya wilayah Ngliman. Namun masalah ini belum jelas, mengingat Kyai Penoppo atau Kyai Ngliman berasal dari Kyai Penoppo (Ngliman) tidak lahir di Nganjuk. Kyai Ngliman merupakan penduduk asli Desa Djojokerto, Kasunanan Surakarta. ${ }^{25} \mathrm{Hal}$ yang sudah pasti adalah adanya pembelaan Kyai Ngliman terhadap masyarakat Desa Ngliman dan sekitarnya terhadap kebijakan kolonial yang memberatkan wilayah tersebut. Peneliti memiliki asumsi bahwa, alasan

23 Auliya Urokhim, "Afdeeling Berbek di Bawah Sosrokoesomo III 18781901", (Surabaya: Universitas Airlangga, 2010), hlm. 39.

${ }^{24}$ ANRI, Staatkundig Overzicht van Nederlandsch Indie, 1837.

25 Dinas Pariwisata dan Kebudayaan Daerah Kabupaten Nganjuk, op, cit., hlm. 4. 
orang Surakarta membela masyarakat Berbek di wilayah pegunungan Nganjuk adalah adanya hubungan masa lalu antara tokoh Penoppo dengan daerah di Berbek, lebih khusus Ngliman. Mengingat bahwa di Nganjuk banyak ditemukan bukti-bukti Islamisasi dari wilayah Jawa Tengah yang periodenya lebih tua daripada kedatangan Penoppo.

Ketika pemberontakan ini berlangsung, usia Kyai Penoppo mencapai 50-55 tahun. ${ }^{26}$ Jika pemberontakan Kyai Penoppo terjadi pada tahun $1832 \mathrm{M}$, maka dapat diperkirakan Kyai Penoppo lahir pada tahun 1777-1782 M. Usia paruh baya dan dapat memobilisasi rakyat pada waktu itu, merupakan kekuatan tersendiri Kyai Penoppo. Kekuatan ini didapat dari dimensi agama dalam gerakan sosial, yang akan dikaji dalam tulisan ini.

\section{b. Sosro Koeseomo I}

Sosro Koesoemo I merupakan Bupati pertama berbek. Mengenai kapan pengangkatan tokoh ini, penulis masih belum mendapatkan data primer untuk menjawab hal tersebut.

Tahun-tahun masa pemerintahannya sering dihubungkan dengan candrasangkala di Masjid Yoni Al

${ }^{26}$ ANRI, Resolusi 21 Pebruari 1832, No. 29., Proses Verbal 24 Januari 1832.
Mubarok Berbek. Ada beberapa sejarahwan lokal yang mencoba menerjemahkan dan men-trasliterasi-kan candrasang-kala tersebut. Pada mimbar masjid yang dimaksud setidaknya terdapat tiga candrasangkala yaitu,

(1) Ratu Nitih Buto Murti bermakna seorang raja yang mulai menata bata dari masjid tersebut dan dimungkinkan pada tahun ini masjid mulai dibangun. Lewat candrasangkala ini dapat ditransli-terasikan tahunnya adalah 1758. Oleh Damari dan Samsul Hadi tahun tersebut diberi satuan AJ (Anno Javanicus) $^{27}$ dan ditambah 72 dalam untuk dikonversikan ke dalam Masehi. Jika yang dimaksud adalah tahun Saka maka konversi tersebut ditambah 78. Maka $1758 \mathrm{~S}$ sama dengan 1836 M. Hal ini juga berlaku pada pembahasan ini. (2) Ratu Pandito Toto Gapuro, seorang raja sekaligus ulama dimungkinkan sedang membangun bagian dari masjid ini, yang memiliki makna angka tahun $1759 \mathrm{~S}$ (1837).

(3) Ratu Pandito Toto Terus, transliterasi angkanya 1759 atau $1837 \mathrm{M}$. Tahun-tahun ini dianggap sebagai tahun

27 Damari dan Samsul Hadi, Kanjeng Raden Tumenggung Sosrokusumo I (Kanjeng Jimat): Bupati Pertama Kabupaten Berbek, (Nganjuk: Kantor Perpustakaan dan Arsip Daerah Kabupaten Nganjuk, 2013), hlm. 62. 
pemerinta-han dari Sosro Koesoemo I.

Namun, meninggalnya Sosro Koesoemo

I adalah tahun $1835 \mathrm{M}$, ini dibuktikan dari tulisan pada makamnya, yaitu tulisan Allah, Muhammad, Ghain, Ra, Nun, Alif, dan Laaillaha Illallah yang berarti Allah, Muhammad, Ghain $=1.000 ; \mathrm{Ra}=200$, Nun $=50$, dan Alif $=1$, sama dengan $1251 \mathrm{H}^{28}$ atau $1835 \mathrm{M}$. Berarti renovasi masjid tersebut dilakukan oleh bupati lain pengganti Sosro Koesoemo I.

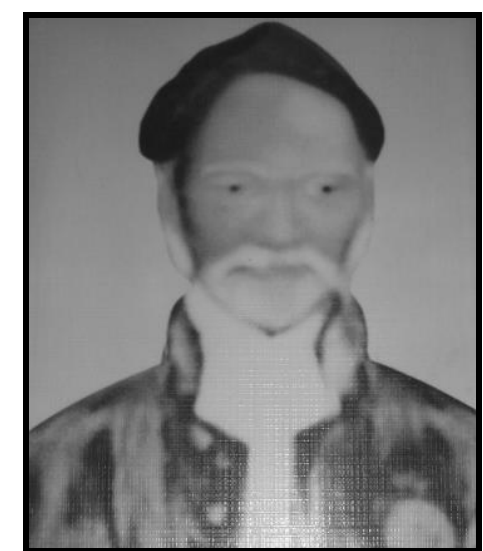

Gambar 1.

Sosro Koesoemo $\left.\right|^{29}$

Pemerintahan Sosro Koe-soemo

I secara de jure dapat dilihat dalam Bijlage, Semarang, 16 Juni 1831, yang didalamnya menyebut nama Sosro Koesomo sebagai bupati Berbek beserta nama-nama perangkat pemerinta-han di Kari-seden Kediri. ${ }^{30}$ Agaknya awal

28 Damari dan Hadi, op, cit., hlm. 66.

${ }^{29}$ Arsip Foto Daerah Kabupaten Nganjuk.

30 Bijlage, Semarang, 16 Juni 1831 dalam ANRI, Besluit, Tanggal 31 Agustus 1830. pemerintahan Sosro Koesoemo I tidak beralwal dari $1831 \mathrm{M}$. Karena terdapat bukti lain dalam tulisan Peter Carey, atau lebih tepatnya pada lampiran peta bertahun $1811 \mathrm{M}$ bahwa wilayah Berbek adalah daerah bagian kekuasaan kolonial pada tahun tersebut. ${ }^{31}$ Namun, tidak ada bukti untuk menyatakan bahwa tahun $1811 \mathrm{M}$ berbek dipimpin oleh Sosro Koesoemo I. Tapi, dimungkinkan tahun 1811 ini Berbek sudah sebagai bagian dari kekuasaan kolonial.

Peneliti memastikan bahwa pemberontakan Ngliman ini dimasa pemerintahan Sosro Koesoemo I. Mengingat ada beberapa rujukan yang berbeda-beda mengenai masalah di era siapa pemberontakan ini terjadi. Seperti dalam tulisan Dinas Pariwisata dan Kebudayaan Daerah Kabupaten Nganjuk bahwa pemberontakan ini terjadi pada masa Sosro Koesoemo II. ${ }^{32}$ Damari, dkk., menyatakan pemberontakan Kyai Ngliman pada masa Sosrodirjo. ${ }^{33}$

31 Peter Carey, Orang Jawa \& Masyarakat Cina 1755-1825), Terjemahan Pustaka Aset, (Jakarta: Pustaka Aset, 1986), hlm. Lampiran peta.

32 Dinas Pariwisata dan Kebudayaan Kabupaten Nganjuk, Bunga Rampai Sejarah dan Ceritera Lokal Kabupaten Nganjuk, (Nganjuk: Dinas Pariwisata dan Kebudayaan Kabupaten Nganjuk, 2006), hlm. 5.

${ }_{33}$ Damri, Samsul Hadi, dan Aries Trio Efendy, Kabupaten Pace dalam Lintas 
Sementara itu, dalam interpretasi peneliti pemberontakan ini terjadi pada Sosro Koesoemo I. Hal ini karena pemerintahan Sosro Koesoemo I berakhir ada $1835 \mathrm{M}$, sesuai dengan penjabaran peneliti diatas, dan tahun 1832 adalah tahun perlawanan Kyai Penoppo. Maka, hal ini dianggap sesuai. Pendapat peneliti ini didukung pula dengan Revolutie, tanggal 21 Pebruari 1832, No.29., Proses Verbal 24 Januari 1832, yang menyatakan bahwa terjadi perlawanan dari tentara Sosro Koesomo kepada pasukan Ngaliman. ${ }^{34}$ Maka tidak ada alasan untuk menafikan hal ini.

\section{Mobilisasi dan Konsolidasi Kyai Penoppo}

Secara historis hanya ada dua data primer terkait perlawanan Kyai Penoppo, yaitu ANRI. Revolutie, tanggal 21 Pebruari 1832, No. 29, dan ANRI, Staatkundig Overzicht van Nederlandsch Indie, 1837. Sumber pertama membahas secara lebih eksplisit pemberontakan Kyai Ngliman dalam proses verbal. Sumber tersebut menjelaskan perlawanan Kyai Ngliman hingga penangkapannya. Sumber kedua, karena

Sejarah, (Nganjuk: Kantor Perpustakaan dan Arsip Kabupaten Nganjuk, 2014), hlm. 32. 34 ANRI. Revolutie, tanggal 21 Pebruari 1832, No. 29., Proses Verbal 24 Januari 1832 (terjemahan). memang laporan politik, mengenai Kyai Penoppo hanya dijelaskan satu paragraf saja, selebihnya adalah peristiwa politik di daerah kolonial di Nusantara.

Peristiwa pemberontakan Kyai Penoppo tersebut nyatanya merupakan aksi yang masiv, terstruktur dan sistematis, serta sangat memengaruhi kehidupan politik kolonial. $\mathrm{Hal}$ ini dikarenakan Penoppo berasil mengumpulkan masa dalam perlawanan ini. Perlawanan didominasi oleh masyarakat sekitar Ngliman hingga pejabad tingkat daerah Berbek ikut termobilisasi olehnya.

Awal dari pemberontakan ini adalah penindasan lewat kerja wajib hingga pajak yang memberatkan. Tanam Paksa ini dimulai tahun 1830 M. Tujuan pokoknya adalah meningkatkan secara pokok kapasitas produksi pertanian orang-orang Jawa demi keuntungan perbendaharaan Kerajaan Belanda. Jika dipandang dari segi ini, Sistem tersebut memang berhasil baik, dengan dihasilkanya sejumlah besar komoditi ekspor, yang penjualannya di Eropa semakin banyak menghasilkan dana untuk menopang posisi keuangan Belanda yang sedang sulit sekali.

Sementara itu, pandangan ulama dalam kepustakaannya, bahwa 
keberhasilan sistem tersebut dalam menghasilkan laba, diiringi dengan kemiskinan yang secara sistematis dari kaum petani Jawa yang dipaksa bekerja. Dengan demikian terdapat fenomena ganjil di Jawa, yaitu bahwa pulau itu setiap tahun menghasilkan kekayaan rata-rata 40 juta gulden, sementara penduduk pulau itu tidak mampu memenuhi kebutuhannya sendiri. 35

Selain Tanam Paksa, pajakpajak yang dibebankan kepada rakyat sangat banyak sekali. Beban pajak ditanggung oleh tiap kabupaten di wilayah kekuasaan kolonial, termasuk Afdeeling Berbek. Pajak tersebut terdiri dari Pajak Pasoemping, Paniwas dan Pegandue. Tiga macam pajak tersebut masi terbagi lagi dengan jenis pajak yang jumlahnya puluhan per macamnya. ${ }^{36}$

Sebelum pemberontakan Kyai Penoppo, kerja wajib dan pajak di Afdeeling Berbek tercatat sejumlah 4 loyang kopi ( \pm 60 pikul) dan pajak sebesar 1.330 gulden untuk pajak. Hal ini sangat berat mengingat jumlah keluarga

35 R.E. Elon, "Kemiskinan dan Kemakmuran Kaum Petani pada Masa Sistem Tanam Paksa di Pulau Jawa", dalam Anne Booth et. al (eds.), terjemahan Mien Joebhaar, Sejarah Ekonomi Indonesia, (Cet. I; Jakarta: LP3ES, 1988), hlm. 41-42.

36 ANRI, Besluit, Semarang, 31 Agustus 1830. La. A. No. 1. di Desa Ngliman hanya 45 kepala keluarga. ${ }^{37}$

Beban-beban tersebut berhasil menyatukan masa. Dalam pergerakanya Penoppo dapat melakukan konsolidasi. ANRI. Revolutie, tanggal 21 Pebruari 1832, No. 29., Proses Verbal 24 Januari 1832 (terjemahan)., menjelaskan: “... pengikut-pengikutnya sebagian besar menjadi murid dan makin bertambah banyak". Dari kalangan atas juga ada beberapa orang yang ikut dalam rombongan ini, yaitu Mas Said dari Berbek dan seorang lagi, dikatakan sebagai orang Jawa dari Gresik berasal dari keluarga Tjondro Koesoemo. Dikatakan pula bahwa "mereka memiliki pengaruh dengan pengikutnya". ${ }^{38} \mathrm{Hal}$ ini menunjukan bahwa konsolidasi yang dilakukan Penoppo bukan hanya kepada petani yang dirugikan terhadap sistem tanah, namun juga para pembesar dan keturunannya yang tidak setuju terhadap sistem tersebut.

37 ANRI, Revolutie, tanggal 21 Pebruari 1832, No. 29., Proses Verbal 24 Januari 1832 (terjemahan). Data ini berbeda dengan data Proses Verbal 28 Januari 1832, No. 40., yang menyatakan bahwa "produksi kopi di desa itu (Desa Ngliman) termasuk Dukuhan sejumlah 600 pikul, dan disana hanya ada 80 kepala keluarga".

38 ANRI, , Revolutie, tanggal 21 Pebruari 1832, No. 29., Proses Verbal 28 Januari 1832, №. 40. 


\section{Benturan Kyai Penoppo dengan Sosro Koeseomo I}

Perlawanan Kyai Penoppo merupakan bentuk pemberontakan skala besar. Hal ini dapat dilihat dari Proses Verbal yang disampaikan $P$ Markus. Kalimat-kalimat represen-tatif tentang hal tersebut seperti, "Dalam waktu dekat kemudian Juru Pajak Ishat dan Mas Penghulu dari Berbek datang padanya, menanyakan sebab kedatangannya (Kyai Penoppo) dengan begitu banyak pengikut..." 39

Kalimat selanjutnya, "Pasukan pribumi berjumlah 1.100 orang diperbatasan bagian selatan dari Residen Rembang telah menyelesaikan seluruhnya melaku-kan penindasan pemberontakan yang akan merusak Kediri (Pemberonta-kan Penoppo)"40

Kemudian, "Untuk masa sekarang persoalan ini akan diselesaikan yang selanjutnya menetapkan peraturan mana yang bertalian dengan makam Ngliman dan termasuk desa-desa yang dipungut pajak. Saya dengan Residen Kediri datang dengan tentara Eropa dari Bojonegoro yang ada di residen itu dan

39 Ibid..

40 Surat dari anggota Dewan Hindia Merkus ditujukan kepada Gubernur Jenderal di Batavia, tertanggal Semarang 4 Pebruari 1832, No. 48. Resolutie, 21 Pebruari 1832, No.29. akan tinggal disana sampai pemberontak tertangkap. Komandan tentara itu adalah Krafft (Kapten).... ${ }^{41}$

Dari kalimat-kalimat tersebut, konklusinya: kolonial mengarahkan pasukan dengan jumlah yang banyak mencapai 1.100 personil. Sebagian pasukan bahkan dari Eropa yang dipimpin oleh Kapten Krafft. Hal ini untuk menghadapi pasukan Ngliman yang jumlahnya juga banyak, dan strategi militer yang tidak kalah modern.

$$
\text { Ada sinyalemen bahwa }
$$

perlawanan Ngliman terjadi sebelum tahun $1832 \mathrm{M}$. Hal ini berkaitan dengan ANRI, Revolutie, tanggal 21 Pebruari 1832, No. 29 yang hanya mengabarkan situasi paska porak poranda yang dilakukan Afdeeling Berbek. Asumsi peneliti ini sangat didukung fakta-fakta bahwa Kyai Penoppo memiliki jumlah pengikut yang banyak. Tentu untuk memobilisasi masa tersebut membutuhkan waktu, tidak hanya dalam hitungan bulan.

Berarti sebelum menghadapi kolonial dengan segala profil tentaranya, Penoppo pada masa awal pergerakanya

${ }^{41}$ Proses verbal penangkapan Kyai Ngliman disusun oleh anggota Dewan Hindia P. Merkus ditunjukan kepada Gubernur Jenderal di Bogor, tertanggal 28 Januari 1832, No. 40. ANRI, Resolutie, 21 Pebruari 1832, No.29. 
sempat menghadapi suzereinitas lokal, yaitu Sosro Koesoemo I, bupati Afdeeling Berbek.

Seperti dalam Proses Verbal 24 Januari 1832., yang menjelaskan bahwa "beberapa waktu yang lalu pasukan Ngliman telah diporak-porandakan oleh tentara Afdeeling Berbek di bawah Sosro Koesoemo (I). 42 Pertemuan dua tokoh besar Nganjuk yang masih berpengaruh hingga sekarang ini adalah nyata terjadi. Jika membaca lebih dalam mengenai Proses Verbal tersebut, maka dapat dipahami bahwa porak-poranda yang dilakukan Sosro Koesoemo I berpengaruh dalam stategi penyerangan Ngliman kedepanya.

Setelah tindakan ofensif dari Sosro Koesoemo I, arah pergerakan Kyai Ngliman lebih mengarah pada jalur diplomasi. Selain itu, Ngliman juga beberapa kali berpindah tempat setelah penyerangan tersebut. Agaknya penyerangan Sosro Koesoemo I membuka celah yang besar bagi pasukan Ngliman, untuk itu diplomasi dirasa tindakan yang paling baik dalam perlawanan ini.

Diplomasi tersebut dimulai ketika ia membuka diskusi dengan Juru Pajak

42 ANRI, Resolutie, 21 Pebruari 1832, No.29. Proses Verbal, 24 Januari 1832. dan Penghulu Afdeeling Berbek, Penghulu Landrad Kediri, Residen Kediri dan lain-lain. Inti dari diskusi tersebut adalah terkabulkanya keinginan dari Ngliman tentang pajak dan pemeliharaan Makam leluhurnya. ${ }^{43}$ Diplomasi ini sepertinya juga tidak berjala terlalu baik, karena kolonial juga merupah gaya penyeranganya.

Jika di awal, Penoppo hanya dihadapi oleh kekuatan Afdeeling Berbek, maka selanjutnya kolonial malah menerjunkan pasukan dengan jumlah yang banyak. Lebih lagi kolonial menambahkan beberapa tentara eropa di bawah Kapten Krafft. Hal ini bisa dianggap sebagai tindakan preventif kolonial agar tidak kembali kecolongan dengan ulah Kyai Penoppo. ${ }^{44}$

Mungkin juga karena sudah memperkirakan kekuatan kolonial yang akan menyerangnya, maka ia dan pengikutnya sering berpindah-pindah. Tercatat perlawananya dimulai di Desa

43 ANRI, Resolutie, 21 Pebruari 1832, No.29. Proses Verbal, 24 Januari 1832.

44 ANRI, Resolutie, 21 Pebruari 1832, No.29. Lihat Laporan penangkapan kyai Ngliman kepada Gubernur Jenderal 28 Januai 1832 No. 40., Keputusan Pemerintah dalam Resolutie, 1 Pebruari 1832 No. 29., Surat Merkus Kepada Gubernur Jenderal 4 Pebruari 1832 No. 49., dan Surat Merkus Kepada Gubernur Jenderal 4 Pebruari 1832 No. 51. 
Ngliman, selanjutnya di Desa Magoeng, pindah lagi ke Desa Ngetos, kemudian pindah ke wilayah utara Afdeeling Nganjuk, yaitu, Desa Gondang (NgetosGondang, $\pm 32 \mathrm{KM}^{45}$ ), pindah lagi ke wilayah yang disebut Paserban Nganjuk, rombongan Kyai Penoppo melakukan pemindahan lagi ke Desa Gemarang Tjaroeban. 46 Perjalananya ini merupakan bagian dari konsolidasi, walaupun alasan utama ketika ia di setiap wilayah ditemui tokoh besar ialah untuk tirakat.

Dalam pelarian yang ia lakukan, terjadi beberapa pertemuan dengan tokoh besar atau perantaranya. Tokoh besar yang sempat berhadapan denganya dalam pemindahan tersebut adalah Pengulu Afdeeling Berbek, Suruhan Asisten Residen Ngawi, Raden Soemo Diwirjo (Pembawa surat Residen Madiun).

Pertemuan dengan tokoh terakhir tersebut nampaknya merupakan hari kesialan Penoppo. Raden Soemo Diwirjo membawa surat dari Residen Madiun kepada Penoppo, surat tersebut berisi ajakan agar Penoppo menghadap Residen Madiun untuk didengar keinginan dan kepentingan Penoppo.

${ }^{45}$ Badan Pusat Statistik Kabupaten Nganjuk, loc, cit., hlm. 10.

46 ANRI, Resolutie, 21 Pebruari 1832, No.29. Proses Verbal, 24 Januari 1832.
Melihat sifat Penoppo, dan situasi pada waktu itu, maka Penoppo menyanggupinya. ${ }^{47}$

Ketika keberangkatannya, rombongan Penoppo diserang pasukan militer. Hal ini yang membuat Penoppo kembali mundur. Ini merupakan serangan kolonial pasca serangan dari pasukan Afdeeling Berbek. Peristiwa berikut merupakan akhir dari pertemuan Kyai Penoppo dan Kanjeng Jimat (Sosro Koesoemo I), selanjutnya Penoppo secara penuh menghadapi perlawanan langsung kolonial dibawah residenresiden Madiun, Ngawi dan tentara Eropa dibawah Krafft.

Pertemuan Penoppo dengan Sosro Koesoemo I dalam ANRI, Resolutie, 21 Pebruari 1832, No.29., hanya dua kali dilakukan, pertama ketika porak poranda tentara Berbek terhadap Ngliman, kedua utusan yang dikirim Sosro Koesomo I untuk melakukan pendektan kepada Penoppo (Ngliman). Secara historis bahwa benturan ini memang ada. Tidak ada kekuatan apapun yang mampu untuk membelokan peristiwa besar ini.

Sampai disini, Perlawanan Penoppo semakin melemah. Tindakan-

47 ANRI, Resolutie, 21 Pebruari 1832, No.29. Proses Verbal, 24 Januari 1832. 
tindakanya selanjutnya didedikasikan untuk kepentingan konsolidasi dalam konteks agama Islam. Pergerakan lanjutan dari Penoppo juga masih diwarnai dengan pelarian, atau menurutnya disebut tirakat. ${ }^{48}$

\section{Kekalahan Kyai Penoppo}

Penoppo hingga perjuanganya berakhir, terus melakukan konsolidasi. la berkeliling dari rumah kerumah sebagai seorang ulama. 49 Perjuanganya tidak berhenti ketika ia dan pasukanya lari dari serangan Residen Madiun. Hal ini terlihat dari perjuangan Kyai Penoppo selanjutnya.

Setelah larinya Penoppo dan rombonganya ketika mendapat serangan dari Residen Madiun, sebelum tanggal 24 Januari 1832 ia sempat melakukan serangan balik di Gumarang, Pasuruan, tercatat dalam arsip ini bahwa penyerangan ini terjadi pukul setengah delapan (tidak diketahui siang atau malam). Penyerangan ini hanaya berlangsung selama 3-4 jam. Karena hal itu kolonial berkesimpulan bahwa pola

\section{Ibid..}

49 Proses verbal penangkapan Kyai Ngliman disusun oleh anggota Dewan Hindia P. Merkus ditujukan kepada Gubernur Jendral di Bogor, tertanggal 28 Januari 1832 no. 40. ANRI, Resolutie 21 Pebruari 1832, No. 29. serangan Penoppo sekarang ini tidak secara tiba-tiba. 50

Setelah penyerangan tersebut, dalam sumber yang sama, menjelaskan bahwa Kyai Ngliman (Penoppo) mendapat panggilan dari Residen Madiun tanpa pasukanya, ${ }^{51}$ dan ini diamini oleh Penoppo. Selanjutnya dapat dipahami bahwa hal ini merupakan siasat kolonial untuk menghentikan pemberontakan Penoppo.

Nasip Penoppo selanjutnya juga sudah dapat dipahami. la kemudian ditangkap. Namun, dalam surat $P$. Merkus ada tendeni peneliti untuk menyatakan penangkapan ini tidak semudah yang dibayangkan. Setelah kedatangna Penoppo di Residen Madiun, P. Merkus menulis, "Petang ini telah menjadi bentrok antara Kyai Ngliman dengan para pengikutnya". Dalam paragraf yang berbeda P. Merkus juga menyatakan bahwa penangkapan Penoppo yang sukses ini, bukan atas dasar menyerahnya Penoppo, namun terjadi perlakuan "penangkapan" terhadap Penoppo. ${ }^{52}$ Perjuangan Kyai

\footnotetext{
$50 \mathrm{lbid} .$.

51 Dan memang tentara kolonial sengaja memisahkan Penoppo dengan pasukanya.

52 Proses verbal penangkapan Kyai Ngliman disusun oleh anggota Dewan Hindia P. Merkus ditujukan kepada Gubernur
} 
Penoppo akhirnya pun harus kalah dengan gerombolan kolonial yang jumlahnya ribuan tersebut.

Penoppo sebagai tahanan politik dijelaskan pada ANRI, Resolutie, 21 Pebruari 1832, No. 29., bahwa "telah disetujui dan disepakati, pertama: Demikian bahwa Kyai Ngliman Guru Ageng sudah ada di Rembang, dan disana ia akan tinggal sebagai tahanan politik". ${ }^{53}$ Dari sumber tersebut nampaknya bahwa penangkapan Penoppo atau pertemuanya dengan Residen Madiun, setidaknya berada di perbatasan bagian dari Karesidenan Madiun yang dekat dengan Karesidenan Rembang. Hal ini dapat dilihat pula, dari surat P. Merkus kepada Gubernur Hindia Belanda bahwa "Pasukan pribumi berjumlah 1.100 orang diperbatasan bagian selatan dari Residen Rembang telah menyelesaikan seluruhnya (melakukan penindasan) pemberontakan yang akan merusak Kediri”.

Penagkapan Kyai Penoppo, juga disebut pada salah satu surat $P$. Merkus sebagai sebuah kabar gembira, "sampailah pada kegembiraan saya diperbolehkan melapor kepada anda,

Jendral di Bogor, tertanggal 28 Januari 1832 no. 40. ANRI, Resolutie 21 Pebruari 1832, No. 29. 1832, No. 29. bahwa di distrik-distrik bagian timur muncul ketenangan, pemimpin rakyat yaitu Kyai Ngliman (Penoppo) telah dihantarkan.... .54

Mengenai masalah kapan tepatnya tanggal penangkapan Penoppo, dalam proses verbal dijelakan bahwa surat P. Markus tentang penagkapan Penoppo tertanggal 28 Januari 1832. Sementara itu, P. Merkus saat menulis surat tersebut menyebutkan tanggal 25 Januari 1832 ketika menerangkan kedatangan Residen Kediri. Pada paragraf-paragraf selanjutnya surat tersebut $\mathrm{P}$. Merkus menjelaskan proses penangkapan Penoppo, yang dalam rangkaian rencana penagkapan ini, Residen Kediri juga turut serta meyumbangkan rencana. Otomatis penangkapan Penoppo sesudah kedatangan Residen Kediri (tanggal 25). Peneliti tendensius untuk menyatakan bahwa tanggal penyerangan Ngliman, adalah pada tanggal 28, karena ini merupakan goal yang diharapkan sejak lama oleh kolonial, untuk itu dimungkinkan pada hari $\mathrm{H}$ penangkapan Penoppo, pada hari itu pula ditulis kabar penangkapan Penoppo, yaitu pada 28

54 Surat dari anggota Dewan Hindia Merkus, ditujukan kepada Gubernur Jendral di Batavia, tertanggal Semarang 4 Pebruari 1832 No. 48. Resolutie, 21 Pebruari 1832, No. 29. 
Januari 1832 M. Pada tanggal itupula pergerakan Penoppo dinyatakan berakhir.

Perjalanan yang sangat panjang dari Kyai Penoppo diakhiri pada 28 Januari 1832 M. Menurut hemat peneliti penerangan ini cenderung prematur. Jika lebih terencana lagi, konsolidasi diperkuat, pelatian para petani, dan perencanaan pelarian yang baik maka perlawanan ini mungkin akan menjadi coretan wajah kolonial yang tebal. Namun, patut dipuji kegigihan dari Penoppo untuk tidak mudah mengalah terhadap kolonial, dan cenderung berani menghadapi kolonial, meskipun harus melawan 3 residensi (Kediri, Ngawi, dan Madiun). Perlawanan Belanda terhadapnya menunjukan bahwa perlawanan ini bersekala besar, perlawanan yang didalamnya terdapat kekuatan agama untuk mengonsolidasi.

\section{KESIMPULAN}

Perlawanan yang dilakukan Kyai Penoppo (Ngliman) dilandasi oleh dimensi agama. Mobilisasi yang dilakukan Ngliman merupakan bagian dari konsolidasi perlawanan secara agama, dalam wujud Penoppo sebagai Kyai atau pemuka agama.
Perlawanan Kyai Ngliman dilakukan pada tahun $1832 \mathrm{M}$. Perlawanan ini awalnya berpusat di Desa Ngliman, Afdeeling Berbek. Dalam perlawanannya, ia bersentuhan dengan penguasa Afdeeling Berbek, yaitu Sosro Koesomo (I). Pertemuan ini benar-benar terjadi, yang tertulis arsip-arsip kolonial dalam penelitian ini.

Akhir dari perlawanan Ngliman adalah kekealahan. Perlawanannya yang represif berhasil dihentikan oleh tentara kolonial yang jumlahnya 1.100 personil belum lagi personil-personil Eropa dibawah kekuasaan Kapten Krafft.

\section{DAFTAR PUSTAKA}

\section{Arsip}

ANRI, Besluit, Semarang, 31 Agustus 1830. La. A. No. 1. Bijlage, Semarang, 16 Juni 1831.

ANRI, No. 1240. Kediri, 28 Agustus 1852.

ANRI, Resolusi 21 Pebruari 1832, No. 29.,

ANRI, Staatkundig Overzicht van Nederlandsch Indie, 1837.

ANRI. Besluit, Semarang, 31 Agustus 1830 La. No. 1.

ANRI. Encyclopaedie van Nederlanche Indie. 1919. Martinus Nijhof: s' Grevenhage.

\section{Buku, Skripsi, Tesis}

Achmad, Sri Wintala. 2016. Babad Giyanti, Pilihan Nagari dan 
Perjanjian Salatiga. Yogyakarta: Araska.

Badan Pusat Statistik Kabupaten Nganjuk. 2017. Kabupaten Nganjuk dalam Angka 2017. Nganjuk: BPS Kabupaten Nganjuk.

Carey, Peter. 1986. Orang Jawa \& Masyarakat Cina 1755-1825), Terjemahan Pustaka Aset. Jakarta: Pustaka Aset.

Carey, Peter. 2011. dalam Seminar Nasional Dies Natalis ke-54 Universitas Diponegoro: Menggali Perjuang-an Pahlawan Diponegoro Untuk Penyusunan Materi Pendidikan Karakter Bangsa di Hotel Horison Semarang, 8 Oktober 2011.

Damari dan Samsul Hadi. 2013. Kanjeng Raden Tumenggung Sosrokusumo I (Kanjeng Jimat): Bupati Pertama Kabupaten Berbek. Nganjuk: Kantor Perpustakaan dan Arsip Daerah Kabupaten Nganjuk.

Damari, Samsul Hadi, dan Aries Trio Efendy. 2014. Kabupaten Pace Dalam Lintas Sejarah. Nganjuk: Kantor Perpustakaan dan Arsip Kabuapten Nganjuk.

Dinas Pariwisata dan Kebudayaan Daerah Kabupaten Nganjuk. 2006. Bunga Ramapi Sejarah dan Ceritera Lokal Kabupaten Nganjuk. Nganjuk: Dinas Pariwisata dan Kebudayaan Kabupaten Nganjuk.

Elon, R.E. 1988. "Kemiskinan dan Kemakmuran Kaum Petani pada Masa Sistem Tanam Paksa di Pulau Jawa", dalam Anne Booth et. al (eds.). Terjemahan Mien Joebhaar. Sejarah Ekonomi Indonesia. Jakarta: LP3ES.
Husnan, Dinul dan Hhd. Sholihin. 2017. "Ulama, Islam, dan Gerakan Sosial-Politik: Reposisi Ulama dalam Gerakan Sosio-Politik di Islam di Indonesia". J Kajian Keislaman dan Kemasyarakatan 2017, 2 (1): 1-25.

Koleksi Arsip Foto Kabupaten Nganjuk.

Mahfud, Muhammad Lauhil. "Gerakan Sosial Pembangunan dan Pelestarian Lingkungan di Jalur Pendakian Gunung Penanggungan Desa Tamiajeng, Kecamatan Trawas, Kabupaten Mojokerto". Surabaya: Universitas Islam Negeri Sunan Ampel.

Manzies, Allan. 2015. History of Religion: Sejarah Kepercayaan dan Agama-agama Besar Dunia. Yogyakarta: Indoliterasi.

Ubaidillah. 2014. "Kyai Kampung dalam Mobilisasi Pelawanan Petani Pada Konflik Lahan di Urutsewu Kebumen". Yogyakarta: Universitas Gajah Mada.

Urokhim, Auliya. 2010. "Afdeeling Berbek di Bawah Sosrokoesomo III 1878-1901". Surabaya: Universitas Airlangga. 